OPEN ACCESS

Edited by:

Jinsong Bian,

National University of Singapore,

Singapore

Reviewed by:

Hussam Wahab Al-Humadi,

University of Babylon, Iraq

Jie Wang,

Henry Ford Health System,

United States

*Correspondence:

Ying Gao

bjgaoying@yahoo.com

Specialty section: This article was submitted to

Translational Pharmacology,

a section of the journal

Frontiers in Pharmacology

Received: 17 December 2021

Accepted: 17 January 2022

Published: 10 February 2022

Citation:

Zhao $X$, Cao $Y$, Jin $H$, Wang $X$, Zhang $L$, Zhang $Y, Y u Y$, Huang $Y$,

Gao $Y$ and Zhang J (2022) Hydrogen

Sulfide Promotes Thyroid Hormone

Synthesis and Secretion by

Upregulating Sirtuin-1.

Front. Pharmacol. 13:838248.

doi: 10.3389/fphar.2022.838248

\section{Hydrogen Sulfide Promotes Thyroid Hormone Synthesis and Secretion by Upregulating Sirtuin-1}

\author{
Xue Zhao ${ }^{1}$, Yedi Cao ${ }^{1}$, Hongfang Jin $^{2}$, Xiuli Wang ${ }^{2}$, Lanbo Zhang ${ }^{3}$, Yang Zhang ${ }^{1}$, Yang Yu ${ }^{1}$, \\ Youyuan Huang ${ }^{1}$, Ying Gao ${ }^{1 \star}$ and Junqing Zhang ${ }^{1}$
}

${ }^{1}$ Department of Endocrinology, Peking University First Hospital, Beijing, China, ${ }^{2}$ Department of Pediatrics, Peking University First Hospital, Beijing, China, ${ }^{3}$ Department of General Surgery, Peking University First Hospital, Beijing, China

Objective: One mechanism of hypothyroidism involves the disruption of thyroid hormone synthesis and secretion by thyrocytes. Hydrogen sulfide $\left(\mathrm{H}_{2} \mathrm{~S}\right)$, as a gas signaling molecule, participates in many physiopathologic processes by upregulating sirtuin-1 (SIRT1). The aim of the current study was to explore whether $\mathrm{H}_{2} \mathrm{~S}$ promotes the synthesis and secretion of thyroid hormones by upregulating SIRT1.

Methods: Real-time PCR and immunohistochemistry were used to detect the mRNA and protein expression of $\mathrm{H}_{2} \mathrm{~S}$-generating enzymes in normal human thyroid tissues. Serum $\mathrm{H}_{2} \mathrm{~S}$ concentrations from hypothyroid patients $(n=32)$ and euthyroid participants $(n=41)$ were detected by $\mathrm{H}_{2} \mathrm{~S}$-selective sensors. Thirty-one Sprague-Dawley rats were divided into control group ( $n=10$ ), hypothyroid group (induced by MMI, $n=10$ ) and hypothyroid + NaHS group $(n=11)$, and the FT4, TT4 and TSH levels were assayed. Human primary thyrocytes were incubated with $\mathrm{H}_{2} \mathrm{~S}$ donor sodium hydrosulfide (NaHS) or $\mathrm{NaHS}$ plus SIRT1 inhibitor (EX527) in vitro. Thyroid hormone synthesis- and secretion-related proteins [thyroid peroxidase (TPO), sodium iodide transporter (NIS), Pendrin, monocarboxylic acid transporter 8 (MCT8)] were analyzed by real-time PCR and Western blot.

Results: $\mathrm{H}_{2} \mathrm{~S}$ levels in serum from hypothyroid patients were decreased compared to those from euthyroid participants $(p<.05)$, and serum $\mathrm{H}_{2}$ S levels were positively correlated with $\mathrm{FT}$, FT4, TT3, and TT4 levels in all subjects (all $p<.0001$ ). In vivo, NaHS promoted thyroid function in hypothyroid rats $(p<.05)$. In vitro, $\mathrm{H}_{2} \mathrm{~S}$ was detected in supernatant, and CBS mRNA was higher than CSE and 3-MPST in human primary thyrocytes $(p<.05)$. The protein levels of TPO, NIS, Pendrin and MCT8 were upregulated in a concentrationdependent manner for NaHS in thyrocytes. After blocking SIRT1 with EX527, we found that the increasing levels of TPO, NIS, Pendrin, and MCT8 and TPO activity were downregulated in thyrocytes incubated with $\mathrm{NaHS}$, and FT4 levels in the cell supernatant were also decreased significantly (all $p<.05$ ).

Conclusion: $\mathrm{H}_{2} \mathrm{~S}$ is mainly generated in thyrocytes by CBS. Serum $\mathrm{H}_{2} \mathrm{~S}$ levels are decreased with hypothyroidism. $\mathrm{H}_{2} \mathrm{~S}$ promotes the synthesis and secretion of thyroid hormones and the expression of related molecules by upregulating SIRT1.

Keywords: hypothyroidism, hydrogen sulfide, sirtuin-1, thyroid hormone synthesis and secretion, thyrocytes 


\section{INTRODUCTION}

Thyroid hormone plays an essential role in our body by regulating the function of physiological systems. Thyroid hormone synthesis and secretion in thyrocytes require related molecules, such as thyroid peroxidase (TPO) (Abramowicz et al., 1992), Pendrin (Taylor et al., 2002), sodium/iodide symporter (NIS) (Bagchi and Fawcett, 1973) and monocarboxylate transporter 8 (MCT8) (Di Cosmo et al., 2010). Hypothyroidism is a widespread endocrine disease that is characterized by reduced thyroid hormone production and secretion. Various diseases can be caused by hypothyroidism, such as heart failure (Biondi, 2012), hypertension (Tiller et al., 2016), reversible dementia (Muangpaisan et al., 2012). Based on a thyroid epidemiological survey published in China, the prevalence of hypothyroidism was $13.95 \%$ (Li et al., 2020). The specific mechanism of hypothyroidism is not completely clear. The most common physiopathologic mechanism of hypothyroidism is the irreversible destruction of thyrocytes (Giordano et al., 1997; Stassi and De Maria, 2002; Ralli et al., 2020). Currently, there has been no therapeutic approach to restore the function of destroyed thyrocytes, and long-term levothyroxine (L-T4) supplementation is an alternative therapy for hypothyroidism (Garber et al., 2012; Biondi and Wartofsky, 2014). Thus, it is critical to protect and maintain thyrocyte function in synthesizing and secreting thyroid hormones, which may be a new approach to hypothyroidism treatment.

Hydrogen sulfide $\left(\mathrm{H}_{2} \mathrm{~S}\right)$ is the third most common endogenous gasotransmitter after carbon monoxide (CO) and nitric oxide (NO). $\mathrm{H}_{2} \mathrm{~S}$ is produced endogenously in the body through both enzymatic and nonenzymatic pathways. Enzymes that can generate $\mathrm{H}_{2} \mathrm{~S}$ mainly include cystathionine $\beta$-synthase (CBS) (Braunstein et al., 1969), cystathionine $\gamma$-lyase (CSE) (Chiku et al., 2009) and 3-mercaptosulfurtransferase (3-MPST) (Shibuya et al., 2009). $\mathrm{H}_{2} \mathrm{~S}$ participates in multiple physiological and pathological processes by a variety of mechanisms (Mustafa et al., 2009; Sen et al., 2012; Untereiner et al., 2016; Wang et al., 2018). Several $\mathrm{H}_{2} \mathrm{~S}$-releasing drugs have been developed to safely treat a wide range of disorders, such as AP39 for oxidant-induced damage (Szczesny et al., 2014) and SG-1002 for heart failure (Elrod et al., 2007).

It was reported that CBS is increased in thyroid malignancies (Turbat-Herrera et al., 2018) and that $\mathrm{H}_{2} \mathrm{~S}$ regulates the growth of different human thyroid carcinoma cell lines in a concentration-dependent manner (Wu et al., 2019). To the best of our knowledge, there has been almost no relevant research on $\mathrm{H}_{2} \mathrm{~S}$ and thyroid function thus far. In the literature, $\mathrm{H}_{2} \mathrm{~S}$ was found to participate in antiatherogenesis by S-sulfhydration of sirtuin-1 (SIRT1) (Du et al., 2019) and attenuate cellular senescence and apoptosis in alveolar epithelial cells by upregulating SIRT1 (Guan et al., 2019). Additionally, it was reported that high glucose exerted an effect on thyroid cell line damage and thyroid hormone deficiency through SIRT1 inactivation (Chen et al., 2019). Thus, we assumed that $\mathrm{H}_{2} \mathrm{~S}$ might play a role in thyroid function by regulating SIRT1. The purpose of the current research was to study the change in $\mathrm{H}_{2} \mathrm{~S}$ levels in hypothyroidism. Moreover, the effect of $\mathrm{H}_{2} \mathrm{~S}$ on thyroid function and the specific mechanism were further explored.

\section{MATERIALS AND METHODS}

\section{Human Subjects and Samples}

A total of 32 hypothyroid patients and 41 euthyroid participants were enrolled in this study. All euthyroid participants had no other thyroid diseases. None of the subjects had any infectious diseases, autoimmune diseases or other diseases that influenced serum $\mathrm{H}_{2} \mathrm{~S}$ levels, such as acquired immune deficiency syndrome (AIDS), chronic hepatitis $\mathrm{B}$, rheumatoid arthritis (RA), systemic lupus erythematosus (SLE), hypertension, atherosclerosis, asthma and inflammatory bowel disease (IBD). Any individuals with evidence of coexisting tumors were also excluded. Five hundred microliters of serum samples were stored at $-80^{\circ} \mathrm{C}$ until use after collecting from all the subjects.

Serial sections of human thyroid tissues were collected from Peking University First Hospital. The samples were obtained from the contralateral lobe with papillary thyroid cancer (PTC), which was confirmed as normal thyroid tissues by pathologists. In addition, human thyroid tissues far away from the PTC lesion $(n=6)$ were collected for primary culture. All the patients were euthyroid and were diagnosed with no autoimmune thyroid diseases.

This research complied with the Helsinki Declaration and was approved by the Biomedical Research Ethics Committee of Peking University First Hospital.

\section{Animal Grouping and Preparation}

To investigate the association between $\mathrm{H}_{2} \mathrm{~S}$ levels and hypothyroidism in vivo, we established a hypothyroid model in rats and observed changes in thyroid function in these models after treatment with the $\mathrm{H}_{2} \mathrm{~S}$ donor sodium hydrosulfide (NaHS). The protocols were approved by the Animal Research Ethics Committee of Peking University First Hospital.

Thirty-one male Sprague-Dawley rats (4 weeks old) were randomly divided into three groups: the control group $(n=$ $10)$, hypothyroid group $(n=10)$ and hypothyroid $+\mathrm{NaHS}$ group $(n=11)$. After adaptive feeding for 1 week, the rats in the hypothyroid group were administered methimazole (MMI, $5 \mathrm{mg} / 100 \mathrm{~g}$, Sigma-Aldrich, St. Louis, MO, United States) daily by intragastric administration for 3 weeks, while the rats in the control group were administered the same dose of saline intragastrically in the control group. The rats in the hypothyroid + NaHS group were injected intraperitoneally daily with NaHS $(56 \mu \mathrm{mol} / \mathrm{kg}$, Sigma-Aldrich) (Zhang et al., 2018) for 3 weeks, 2 hbefore a daily $5 \mathrm{mg} / 100 \mathrm{~g}$ MMI treatment, while the rats in the control and hypothyroid groups were injected with the same dose of saline intraperitoneally in the control and hypothyroid groups.

Furthermore, rats were anesthetized by ketamine after 3 weeks of saline, MMI or MMI + NaHS challenge. The bilateral total thyroid glands were removed rapidly, the weight was measured, and then the thyroid glands were stored in $-80{ }^{\circ} \mathrm{C}$ or $10 \%$ neutral 
phosphate-buffered formalin. Serum samples from the rats in the three different groups were stored at $-80^{\circ} \mathrm{C}$ until use.

\section{Thyroid Function Detection}

Thyroid function in serum from the hypothyroid and euthyroid groups was assayed by chemiluminescence immunoassay (ADVIA Centaur; Siemens Healthcare Diagnostics, Camberley, $\mathrm{UK}$ ). The detection range for free triiodothyronine (FT3): 3.50-6.50 pmol/L, free thyroxine (FT4): $11.48-22.70 \mathrm{pmol} / \mathrm{L}$, total triiodothyronine (TT3): $0.92-2.79 \mathrm{nmol} / \mathrm{L}$, total thyroxine (TT4): 58.1-140.60 nmol/L, thyroid-stimulating hormone (TSH): 0.55-4.78 $\mu \mathrm{IU} / \mathrm{ml}$. The lower detection limit for FT4 was $1.3 \mathrm{pmol} / \mathrm{L}$.

Serum FT4 and T4 levels in three different groups of rats were detected by ELISA (CUSABIO, Wuhan, China), and TSH levels were measured by radioimmunoassay (FURUIRUNZE, Beijing, China). All procedures were conducted according to the protocols provided by the manufacturers. Intra-assay coefficients of variation were all less than $15 \%$, and all serum samples were detected together to eliminate interassay variation.

\section{Measurement of $\mathrm{H}_{\mathbf{2}} \mathrm{S}$ Levels}

The $\mathrm{H}_{2} \mathrm{~S}$ levels in serum samples from the subjects and rats were measured by using the free radical analyzer TBR4100 with an $\mathrm{H}_{2} \mathrm{~S}$ -selective sensor (ISO- $\mathrm{H}_{2} \mathrm{~S}-100$, WPI, China) as reported previously (Huang et al., 2015). Firstly, the $\mathrm{H}_{2} \mathrm{~S}$-selective sensor was polarized with phosphate buffered saline (PBS) buffer, and then the calibration curve with a plot of the signal output ( $\mathrm{pA})-\mathrm{H}_{2} \mathrm{~S}$ concentration was generated as follows. The sensor tip was sequentially immersed in PBS buffer containing different concentrations of $\mathrm{Na} 2 \mathrm{~S}$. Then, the calibration curve was completed by pA, which corresponded to the concentration of $\mathrm{H}_{2} \mathrm{~S}$. Second, the sensor tip was immersed into every sample to assay the $\mathrm{H}_{2} \mathrm{~S}$ concentration according to the calibration curve.

\section{Histopathological Changes in Thyroid Tissues From Rats}

Thyroid glands from rats in three different groups (control group, hypothyroid group and hypothyroid $+\mathrm{NaHS}$ group) were surgically removed and embedded in paraffin after fixing in $10 \%$ neutral phosphate-buffered formalin. Then, $5 \mu \mathrm{m}$ thick sections were prepared for hematoxylin and eosin (H\&E) staining to assess the pathological characteristics of thyroids from rats.

\section{Immunohistochemistry Staining (IHC) of Human Thyroid Slides for $\mathrm{H}_{2} \mathrm{~S}$ Generation-Related Enzyme Detection}

To test the expression of $\mathrm{H}_{2} \mathrm{~S}$-generating enzymes, including CBS, CSE and 3-MPST, in the human thyroid, the thyroid tissue sections mentioned above were microwaved in citrate buffer or EDTA buffer for $15 \mathrm{~min}$, and then 3\% hydrogen peroxide was used to block endogenous peroxidase. After blocking with 3\% bovine serum albumin (BSA, Sigma-Aldrich), tissue slides were incubated with the following primary antibodies at $4^{\circ} \mathrm{C}$ overnight:
CBS antibody (1:200), CSE antibody (1:25), and 3-MPST antibody (1:25) (all from Santa Cruz, California, United States). Then, the slides were incubated with secondary antibody for $60 \mathrm{~min}$. Finally, 3,3'-diaminobenzidine (DAB) staining (ZSGB-BIO, Beijing, China) was used to detect positive areas, which were monitored by an Olympus BX51T microscope (Tokyo, Japan).

\section{The Isolation and Culture of Human Primary Thyrocytes}

The thyrocyte culture method was performed on the basis of a method described previously (Nilsson et al., 1996; Zhao et al., 2018). The thyroid tissues were digested with type II collagenase (Gibco, Grand Island, New York, United States). After $1 \mathrm{~h}$ at $37^{\circ} \mathrm{C}$, thyrocytes were digested with $0.05 \%$ trypsin (Gibco) for $5 \mathrm{~min}$. After filtering through sterile filters, thyroid follicles were collected by centrifugation at $500 \mathrm{~g}$ for $3 \mathrm{~min}$. Cells were cultured at $37{ }^{\circ} \mathrm{C}$ and $5 \% \mathrm{CO}_{2}$ in RPMI 1640 medium containing $10 \%$ fetal bovine serum (FBS), 1\% L-glutamine and 1\% (v/v) penicillin/ streptomycin (all from Gibco) supplemented with $1 \mathrm{mIU} / \mathrm{ml}$ bovine TSH (Sigma-Aldrich).

In addition, to detect FT4 levels in primary thyrocyte culture supernatant, thyrocytes were cultured with RPMI 1640 medium containing 1\% charcoal-stripped fetal bovine serum (Biological Industries, Kibbutz Beit Haemek, Israel), 1\% L-glutamine and 1\% (v/v) penicillin/streptomycin (all from Gibco) and supplemented with $1 \mathrm{mIU} / \mathrm{ml}$ bovine TSH and $10^{-8} \mathrm{M}$ sodium iodide (all from Sigma-Aldrich). $\mathrm{H}_{2} \mathrm{~S}$ levels in primary thyrocyte culture supernatant were measured as described in Methods Section 2.4.

\section{Detection of $\mathrm{H}_{2} \mathrm{~S}$ in Human Primary Thyrocytes by Fluorescent Probe in situ} Primary thyrocytes were cultured in Lab-Tek chambered cover glass (Thermo Fisher, Woolston, UK) and incubated with $\mathrm{H}_{2} \mathrm{~S}$ fluorescent probes $(1 \mu \mathrm{M}$, Cayman Chemical Company, Michigan, United States) for $30 \mathrm{~min}$. Then, the cells were washed and fixed with $10 \%$ neutral phosphate-buffered formalin for $30 \mathrm{~min}$. A TCS SP5 confocal laser-scanning microscope TCS SP5 (Leica, Wetzlar, Germany) was used to obtain fluorescent images.

\section{Human Thyrocyte Stimulation With NaHS and EX527 in vitro}

To examine the effect of different concentrations of $\mathrm{H}_{2} \mathrm{~S}$ on thyroid hormone synthesis and secretion-related molecules, thyrocytes were cultured as described in Methods Section 2.7. When the cell density reached approximately $60 \%$, different concentrations of NaHS were added. Finally, the cells were collected after $48 \mathrm{~h}$ for Western blot to detect the changes in thyroid hormone synthesis- and secretion-related proteins.

To verify whether $\mathrm{H}_{2} \mathrm{~S}$ exerted its effect on FT4 levels and TPO, Pendrin, NIS and MCT8 expression or TPO activity through SIRT1, thyrocytes were divided into three groups: the control group, NaHS group, and NaHS + EX527 group. The 
TABLE 1 | Primer sequences used for real-time PCR.

\begin{tabular}{llll}
\hline Gene & & \multicolumn{1}{c}{ Primer sequence (5'-3') } & Product bp \\
\hline TPO & Forward & CTGTCACGCTGGTTATGGC & 19 \\
& Reverse & GCTAGAGACACGAGACTCCTCA & 22 \\
Pendrin & Forward & CATCAAGACATATCTCAGTTGGACCT & 26 \\
& Reverse & ACAGTTCCATTGCTGCTGGAT & 21 \\
NIS & Forward & GTCCTTCAGGGCTCCTTCACC & 21 \\
& Reverse & CTGCTCGCTGGGTGGGTACA & 20 \\
MCT8 & Forward & CCACGCCTACGGTAGAGAC & 19 \\
& Reverse & CAGAGTTATGGATCCGAAGATG & 23 \\
CBS & Forward & AATGGTGACGCTTGGGAA & 18 \\
& Reverse & TGAGGCGGATCTGTITGA & 18 \\
CSE & Forward & AAGACGCCTCCTCACAAGGT & 20 \\
& Reverse & ATATTCAAAACCCGAGTGCTGG & 22 \\
$3-M P S T$ & Forward & CGGAGTCTCCTCCCTTGGT & 20 \\
& Reverse & CCTCCCTAAGATGCAGCTCG & 20 \\
GAPDH & Forward & GGAGCGAGATCCCTCCAAAT & 21 \\
& Reverse & GGCTGTTGTCATACTTCTCATGG & 23
\end{tabular}

NaHS group was challenged with $100 \mu \mathrm{M}$ NaHS. The NaHS + EX527 group was incubated with $10 \mu \mathrm{M}$ EX527 (Sigma-Aldrich), a SIRT1 inhibitor, and $100 \mu \mathrm{M}$ NaHS was added $4 \mathrm{~h}$ after EX527 treatment. Finally, the cells of all three groups were collected after $24 \mathrm{~h}$ for real-time PCR or $48 \mathrm{~h}$ for Western blot and TPO activity measurements, and the supernatant was also collected after $48 \mathrm{~h}$ for FT4 detection.

\section{Real-Time Polymerase Chain Reaction (Real-Time PCR) to Measure the mRNA Levels of Thyroid Hormone Synthesis- and Secretion-Related and $\mathrm{H}_{2} \mathrm{~S}$ Generation-Related Molecules in Human Thyrocytes}

TRIzol reagent (Life Technologies, Carlsbad, California, U.S.A.) was used to extract total RNA of human primary thyrocytes. The RNA was reverse transcribed into cDNA using the High Capacity cDNA Reverse Transcription Kit (Life Technologies). The primers for TPO, NIS, Pendrin, MCT8, CBS, CSE, 3-MPST, and GAPDH are listed in Table 1. Detection of mRNA expression was carried out by the SYBR Green Supermix Kit (Thermo Fisher) and 7,500 realtime PCR system (Applied Biosystems, Foster City, CA, United States). Relative target gene expression was quantified by the $2-\triangle \triangle \mathrm{Ct}$ method using GAPDH expression for normalization.

\section{Western Blot Analysis of the Protein Levels of Thyroid Hormone Synthesis- and Secretion-Related Molecules in Human Thyrocytes}

Primary thyrocyte lysates ( $25 \mu \mathrm{g}$ per sample) were separated by sodium dodecyl sulfate-polyacrylamide gel (10\%) electrophoresis and spotted onto nitrocellulose (NC) membranes. The NC bands were separately incubated with the following primary antibodies at $4^{\circ} \mathrm{C}$ overnight: NIS antibody (1:2000; Biorbyt, Cambridge, UK),
TPO antibody (1:400; Santa Cruz, California, United States), Pendrin antibody (1:500; Abcam, Cambridge, UK), MCT8 antibody (1:500; Proteintech, Wuhan, China), SIRT1 antibody (1:500, Abcam), and GAPDH antibody (1:2000; TransGen Biotech, Beijing, China). The bands were then incubated with secondary antibodies (1:5000; ZSGB-BIO) for $1 \mathrm{~h}$. The immunoreactions were detected by an enhanced chemiluminescence system (Millipore, Yonezawa, Japan). ImageJ software (developed at the National Institutes of Health) was used to quantify the relative staining intensity.

\section{Enzymatic Activity of TPO in Human Primary Thyrocytes}

We assayed TPO activity as previously described (Godlewska et al., 2014). The cells were washed three times. Then, $500 \mu \mathrm{L}$ of reaction mixture was added $[100 \mu \mathrm{M}$ potassium iodide (Sigma-Aldrich), $50 \mu \mathrm{M}$ Amplex Red (Life Technologies) and $200 \mathrm{U} / \mathrm{ml}$ superoxide dismutase (Sigma-Aldrich)]. The reaction was started via adding hydrogen peroxide (Life Technologies). Twenty-microliter aliquots were mixed with $80 \mu \mathrm{L}$ inhibition mixture $[500 \mathrm{U} / \mathrm{ml}$ catalase (Solaria, Beijing, China) and 100 $\mathrm{U} / \mathrm{ml}$ SOD (Sigma-Aldrich)] after removing every minute for $8 \mathrm{~min}$. The fluorescence was assayed in a microtiter reader (Bio Tek, Vermont, United States) by using excitation at $530 \mathrm{~nm}$ and emission at $590 \mathrm{~nm}$. The detection values were corrected by the corresponding protein quality.

\section{Statistical Analysis}

All experimental data were analyzed by using SPSS 25.0 (IBM, United States). Normally distributed variables are expressed as the mean \pm standard deviation (SD) or mean \pm standard error (SEM), and nonnormally distributed variables are expressed as the median and interquartile range. Means were compared via one-way ANOVA for comparisons among multiple groups and independent $t$ tests for comparisons between the two groups. Medians were compared by Kruskal-Wallis test among multiple groups and Mann-Whitney test between the two groups. Bivariate relationships were performed with a Pearson or Spearman rank correlation model. $p<.05$ was considered as statistically significant.

\section{RESULTS}

\section{Human Primary Thyrocytes Produced $\mathrm{H}_{2} \mathrm{~S}$, and $\mathrm{CBS}$ Was the Main $\mathrm{H}_{2} \mathrm{~S}$-Generating Enzyme in Normal Thyrocytes}

In human primary thyrocytes, we measured $\mathrm{H}_{2} \mathrm{~S}$ production by an in situ fluorescent probe (Figure 1A), and at different culture days, $\mathrm{H}_{2} \mathrm{~S}$ was also detected in supernatants by a $\mathrm{H}_{2} \mathrm{~S}$-selective sensor (Figure 1B), which indicated the capacity of thyrocytes to produce $\mathrm{H}_{2} \mathrm{~S}$. We further assayed $\mathrm{H}_{2} \mathrm{~S}$-generating enzymes in human thyroid tissues by IHC and found that CBS, CSE, and 3MPST all existed in thyrocytes and were mainly localized in the cytoplasm (Figure 1C). Then, we observed significantly higher 

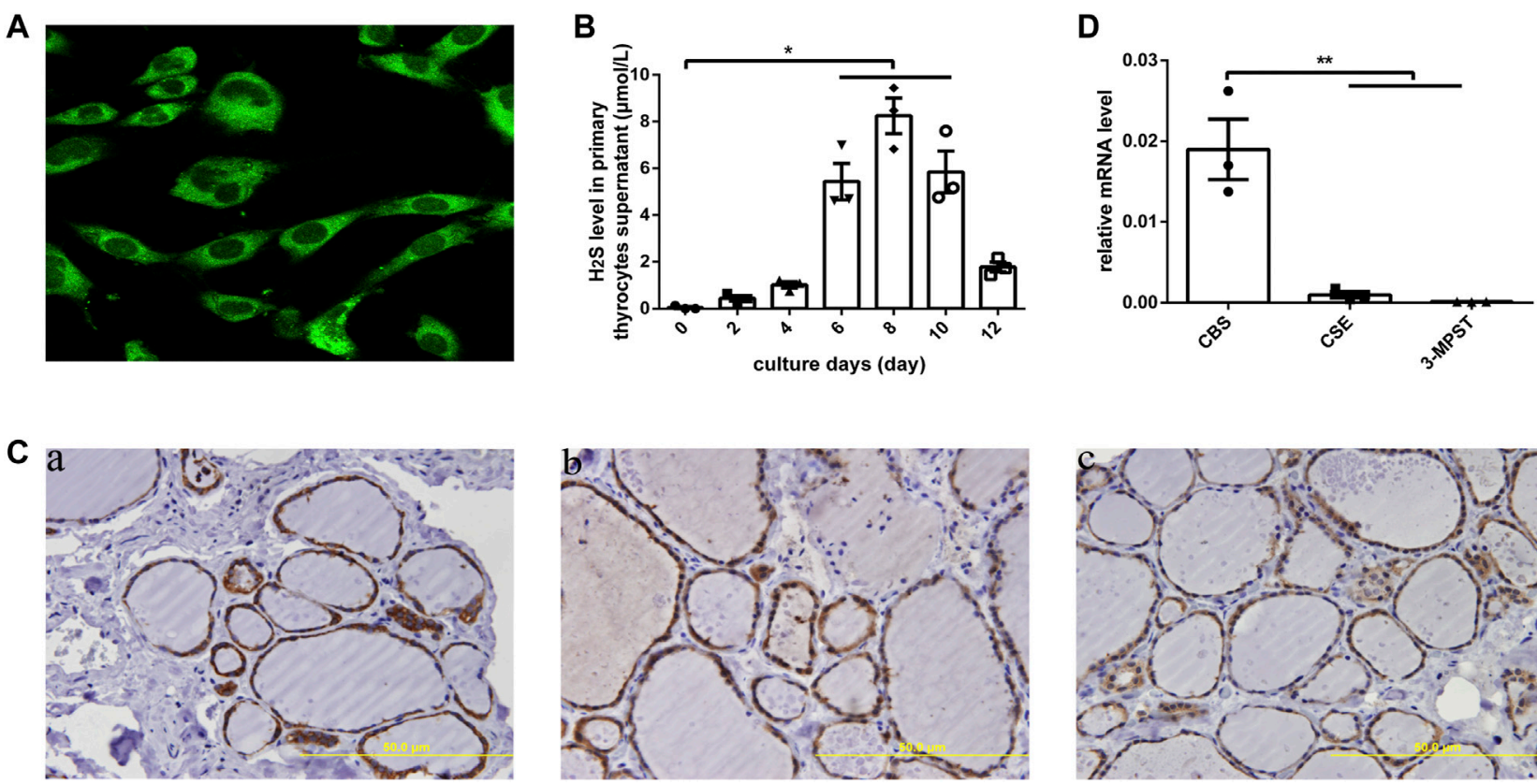

FIGURE 1 $\mid \mathrm{H}_{2} \mathrm{~S}$ generation and related enzymes in human thyroid. (A) $\mathrm{H}_{2} \mathrm{~S}$ generation in human primary thyrocytes was measured by an in situ fluorescent $\mathrm{H}_{2} \mathrm{~S}$ probe. (B) $\mathrm{H}_{2} \mathrm{~S}$ levels in supernatants were detected by $\mathrm{H}_{2} \mathrm{~S}$-selective sensor in human primary thyrocytes with different culture days. (C) The enzymes that generated $\mathrm{H}_{2} \mathrm{~S}$ were detected by immunohistochemistry staining in human thyroid tissues. All of them were located in the cytoplasm of thyrocytes. CBS (a), CSE (b), 3-MPST (c). (D) The enzymes that generated $\mathrm{H}_{2} \mathrm{~S}$ in human primary thyrocytes were detected by real-time PCR. The level of CBS mRNA expression is the highest. ${ }^{\star} p<.05$, ${ }^{\star \star} p<$ .01. CBS, cystathionine $\beta$-synthase; CSE, cystathionine $\gamma$-lyase; 3-MPST, 3-mercaptosulfurtransferase; $\mathrm{H}_{2} \mathrm{~S}$, hydrogen sulfide. Data are expressed as the mean \pm SEM, and all experiments were performed independently three times.

TABLE 2 | Demographic and clinical characteristics of the euthyroid and hypothyroid groups.

\section{Euthyroid participants $(n=$}

41)

\begin{tabular}{ll}
\hline Sex(M/F) & $6 / 35$ \\
Age (years) & $46.1 \pm 14.5$ \\
FT3 $(\mathrm{pmol} / \mathrm{L})$ & $4.9 \pm 0.5$ \\
FT4 $(\mathrm{pmol} / \mathrm{L})$ & $13.8(13.2,15.1)$ \\
TT3 $(\mathrm{nmol} / \mathrm{L})$ & $1.8 \pm 0.3$ \\
TT4 $(\mathrm{nmol} / \mathrm{L})$ & $97.6 \pm 17.6$ \\
TSH $(\mu \mathrm{l} / \mathrm{m} / \mathrm{ml})$ & $1.5(0.9,1.9)$
\end{tabular}

Data are the mean $\pm S D$, or median and interquartile range. Continuous variables with normal distributions were compared between two groups using independent t tests, and variables with nonnormal distributions were compared between two groups by Mann-Whitney tests. The $\chi 2$ test was used to compare categorical variables between the two groups. F, female; M, male; FT3, free triiodothyronine; FT4, free triiodothyronine; $\Pi T 3$, total triiodothyronine; $\Pi 4$, total thyroxine; and TSH, thyroid-stimulating hormone.

mRNA expression for CBS than CSE and 3-MPST in human primary thyrocytes, which illustrated that $\mathrm{CBS}$ is the main $\mathrm{H}_{2} \mathrm{~S}$-generating enzyme in the thyroid (Figure 1D).

\section{Decreased $\mathrm{H}_{2} \mathrm{~S}$ Content in Serum From Hypothyroid Patients}

We further compared $\mathrm{H}_{2} \mathrm{~S}$ levels between the euthyroid group and hypothyroid group. The clinical features of the subjects are shown in Table 2. The $\mathrm{H}_{2} \mathrm{~S}$ levels in serum from the hypothyroid patient group were significantly lower than those in the euthyroid group $[1.46(0.97,1.76)$ vs. $3.30(2.54,3.86), p<.0001]$ (Figure 2A). As shown in Figure 2B, we observed that the $\mathrm{H}_{2} \mathrm{~S}$ level was positively correlated with the serum FT3 level $(r=0.670, p<.0001)$, FT4 level $(r=0.590, p<.0001)$, TT3 level $(r=0.678, p<.0001)$, and TT4 level $(r=0.684, p<.0001)$ in all subjects and negatively correlated with the serum TSH level $(r=-0.718, p<.0001)$. All the results indicated that $\mathrm{H}_{2} \mathrm{~S}$ might be associated with thyroid hormone production.

\section{NaHS Treatment Improved Thyroid Function in Hypothyroid Rats}

In the hypothyroid model of rats, the $\mathrm{H}_{2} \mathrm{~S}$ levels in serum also decreased compared to those in the control group (Figure 3A). After administration of $\mathrm{NaHS}$, the $\mathrm{H}_{2} \mathrm{~S}$ level was markedly increased (Figure 3A). $\mathrm{H}_{2} \mathrm{~S}$ levels in serum were also positively correlated with serum FT4 levels $(r=0.752, p<.0001)$ and TT4 levels $(r=0.730, p<.0001)$ and negatively correlated with serum TSH levels $(r=-0.680, p<.0001)$ (Supplementary Figure S1). This further verified our observation of decreased $\mathrm{H}_{2} \mathrm{~S}$ levels in the serum from hypothyroid patients.

To identify the effect of $\mathrm{H}_{2} \mathrm{~S}$ on thyroid function, thyroid hormone levels were compared in the control, hypothyroid, and hypothyroid + NaHS groups of Sprague-Dawley rats. Compared with the control group, FT4 and TT4 levels decreased significantly in the hypothyroid group, and TSH levels 

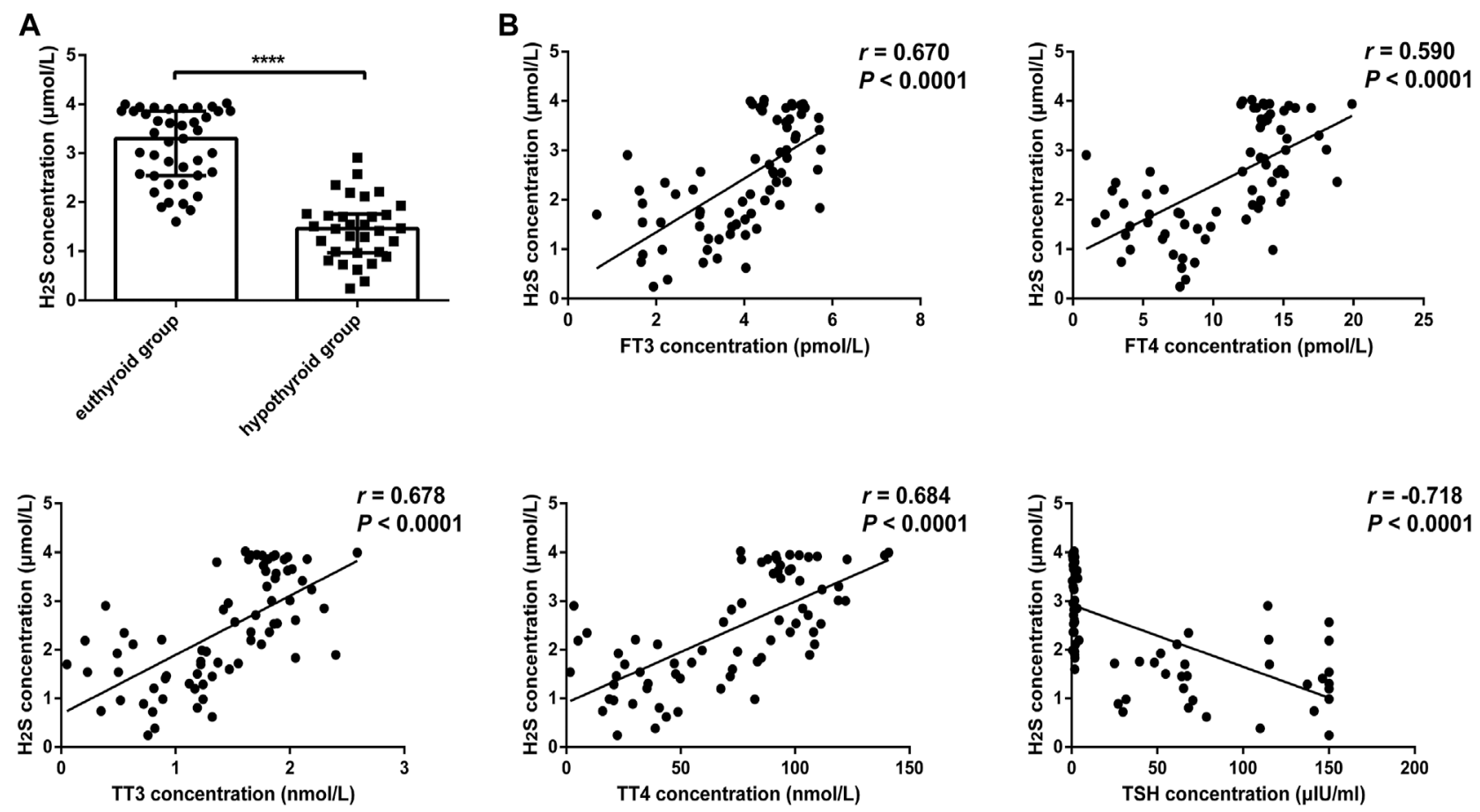

FIGURE 2 C Comparison of $\mathrm{H}_{2} \mathrm{~S}$ levels in serum from euthyroid and hypothyroid groups in human and the relationship between $\mathrm{H}_{2} \mathrm{~S}$ levels and thyroid function. (A) $\mathrm{H}_{2} \mathrm{~S}$ levels in serum from the euthyroid $(n=41)$ and hypothyroid $(n=32)$ groups were analyzed by $\mathrm{H}_{2} \mathrm{~S}$-selective sensors. The $\mathrm{H}_{2} \mathrm{~S}$ level was significantly lower in the hypothyroid group. (B) Correlations between $\mathrm{H}_{2} \mathrm{~S}$ levels and thyroid function in serum samples. $\mathrm{H}_{2} \mathrm{~S}$ levels were positively correlated with FT3, FT4, TT3, and TT4 levels and negatively correlated with TSH levels. A bivariate correlation analysis was performed by using Spearman rank test. $r$ represents correlation coefficient. ${ }^{\star \star \star \star} p<$ .0001. Data in Figure 2A are expressed as the median and interquartile range. $\mathrm{H}_{2} \mathrm{~S}$, hydrogen sulfide; $\mathrm{FT} 3$, free triiodothyronine; FT4, free triiodothyronine; $T T 3$, total triiodothyronine; TT4, total thyroxine; TSH, thyroid-stimulating hormone.

increased obviously, whereas NaHS treatment clearly reversed the above-described effects in rats (Figure 3B).

Next, to compare the thyroid morphology in the three groups, we performed a gross thyroid inspection in rats and found that the thyroid gland in the hypothyroid group was visually enlarged compared with that in the control group. Meanwhile, thyroid cell hypertrophy and abnormal follicular architecture were also found in the hypothyroid group compared with the control group. The thyroid follicles in the hypothyroid group were lined by hypertrophic and hyperplastic thyrocytes and contained scant colloids. However, these effects in the hypothyroid group were alleviated to a certain extent in the hypothyroid + NaHS group (Figure 3C). This result suggested that NaHS treatment may restore thyroid function and relieve morphological changes of thyrocytes involved in hypothyroidism.

\section{Effect of $\mathrm{H}_{2} \mathrm{~S}$ on Thyroid Hormone Synthesis-Related Molecules and TPO Activity in Human Primary Thyrocytes}

To further explore the potential mechanisms of $\mathrm{H}_{2} \mathrm{~S}$ on the synthesis and secretion of thyroid hormones in thyrocytes, we detected synthesis- and secretion-related proteins, such as TPO, NIS, Pendrin and MCT8. As shown in Figure 4, the protein levels of TPO, NIS, Pendrin and MCT8 in human primary thyrocytes were upregulated in a concentrationdependent manner by NaHS.

Since TPO activity plays an essential role in mediating thyroid hormone synthesis, we compared TPO activity in human primary thyrocytes treated with or without NaHS. We found that TPO activity was upregulated when thyrocytes were challenged with NaHS (Figure 5C).

\section{$\mathrm{H}_{2} \mathrm{~S}$ Promoted Thyroid Hormone Synthesis and Secretion by Increasing the Expression of Related Proteins and TPO Activity via SIRT1 in Human Primary Thyrocytes}

$\mathrm{H}_{2} \mathrm{~S}$ is involved in some physio-pathological processes by regulating SIRT1 (Xin et al., 2016; Guan et al., 2020). To investigate whether $\mathrm{H}_{2} \mathrm{~S}$ exerted functions on regulating TPO, NIS, Pendrin and MCT8 expression through SIRT1, human primary thyrocytes were divided into control, NaHS or NaHS + EX527 groups. After stimulating with NaHS, both the mRNA and protein expression levels of TPO, NIS and Pendrin were upregulated, and MCT8 was upregulated at the protein level (Figures 5A,B). However, pretreating thyrocytes with EX527 clearly reversed the above-described effects (Figures 5A,B).

We subsequently identified whether $\mathrm{H}_{2} \mathrm{~S}$ promoted TPO activity by regulating SIRT1 in human primary thyrocytes. As 

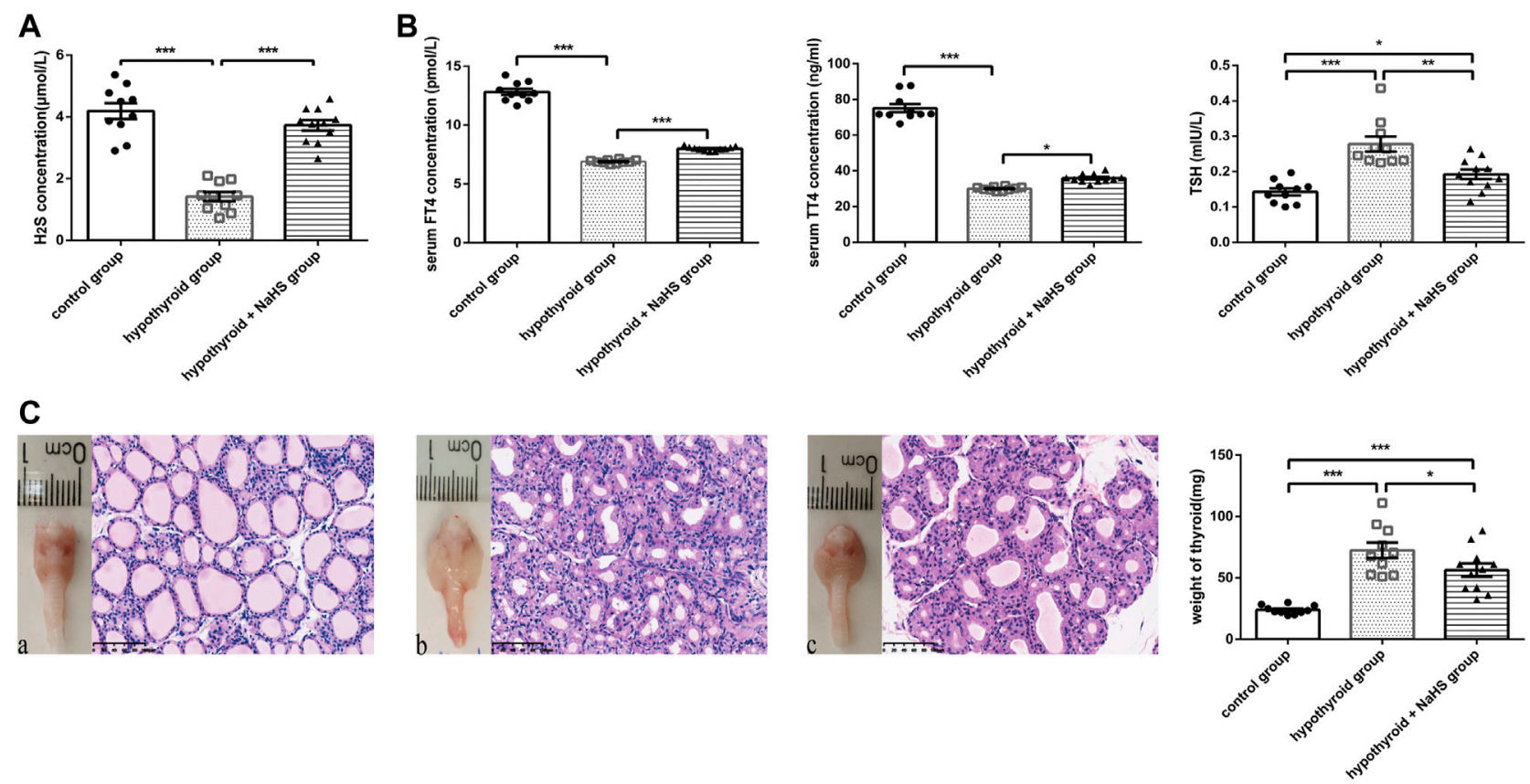

FIGURE 3 | The effect of $\mathrm{H}_{2} \mathrm{~S}$ on thyroid function in hypothyroid rats. (A) The $\mathrm{H}_{2} \mathrm{~S}$ levels in rat serum of control group $(n=10)$, hypothyroid group $(n=10)$ and hypothyroid $+\mathrm{NaHS}$ group $(n=11)$ were analyzed by $\mathrm{H}_{2} \mathrm{~S}$-selective sensor. $\mathrm{H}_{2} \mathrm{~S}$ level was significantly lower in hypothyroid group and $\mathrm{NaHS}$ treatment improved $\mathrm{H}_{2} \mathrm{~S}$ level in hypothyroid rats. (B) Serum FT4 and TT4 levels in the control group $(n=10)$, hypothyroid group $(n=10)$ and hypothyroid $+\operatorname{NaHS}$ group $(n=11)$ were measured by ELISA, and TSH levels were assayed by radioimmunoassay. NaHS treatment improved thyroid function in hypothyroid rats. (C) Anterior views of thyroid glands and their related histological changes with H\&E staining (magnification, $\times 200$ ), and the weight of thyroids in different groups are shown. Control group (a), hypothyroid group (b), hypothyroid + NaHS group (c). NaHS treatment alleviated thyroid enlargement in hypothyroid rats. ${ }^{*} p<.05,{ }^{* \star} p<.01,{ }^{* \star *} p<.001,{ }^{* \star * *} p<.0001$. Data are expressed as the mean $\pm \mathrm{SEM}$ and $n=10-11$ per group. $\mathrm{H}_{2} \mathrm{~S}$, hydrogen sulfide; NaHS, sodium hydrosulfide; FT4, free triiodothyronine; TT4, total thyroxine; TSH, thyroidstimulating hormone.

shown in Figure 5C, the increased extracellular TPO activity in thyrocytes after incubation with NaHS was suppressed by EX527.

Accordingly, the FT4 level in the human primary thyroid cell supernatant was increased after incubation with $\mathrm{NaHS}$, and after blocking SIRT1 with EX527, the FT4 level was decreased (Figure 5D).

\section{DISCUSSION}

Hypothyroidism is an endocrinopathy caused by thyroid hormone production and secretion deficiency in the thyroid gland. The mechanism of hypothyroidism involves the destruction of thyroid cell functions that synthesize thyroid hormones (Gillam and Kopp, 2001). In our study, we firstly demonstrated that $\mathrm{H}_{2} \mathrm{~S}$, a gas signaling molecule, might have a protective effect on thyroid hormone synthesis and secretion by promoting the expression levels of thyroid hormone synthesisrelated proteins and upregulating TPO activity through SIRT1.

$\mathrm{H}_{2} \mathrm{~S}$ is produced in mammals by three major $\mathrm{H}_{2} \mathrm{~S}$-generating enzymes: CBS, CSE, and 3-MPST (Braunstein et al., 1969; Chiku et al., 2009; Shibuya et al., 2009). CBS appears abundantly in the central nervous system, and CSE is mainly found in cardiovascular tissues (Pan et al., 2012). In our research, we found that $\mathrm{H}_{2} \mathrm{~S}$ production in thyrocytes, and CBS, CSE, and 3-
MPST all existed in thyrocytes, which indicated that $\mathrm{H}_{2} \mathrm{~S}$ was automatically generated by thyroid cells. According to the difference in mRNA expression, CBS was the main $\mathrm{H}_{2} \mathrm{~S}$-generating enzyme in the thyroid, further illustrating that the expression of $\mathrm{H}_{2} \mathrm{~S}$-generating enzymes was tissue specific.

There have been extensive reports about the protective effect of $\mathrm{H}_{2} \mathrm{~S}$ on various diseases by diverse $\mathrm{S}$-sulfhydration molecules. Tian et al. reported that $\mathrm{H}_{2} \mathrm{~S}$ inhibited the proliferation of vascular smooth muscle cells by persulfidating FOXO1 at Cys457 to protect vascular structure, demonstrating that $\mathrm{H}_{2} \mathrm{~S}$ had a beneficial effect on cardiovascular diseases (Tian et al., 2021). $\mathrm{H}_{2} \mathrm{~S}$ levels were decreased in ischemic vascular dementia, and NaHS protected against neuronal injury in a vascular dementia rat model (Zhang et al., 2009). Du et al. also proposed that $\mathrm{CSE} / \mathrm{H}_{2} \mathrm{~S}$ promoted the deacetylation activity of SIRT1 by sulfhydrating SIRT1 and thus has an antiatherogenetic role (Du et al., 2019). In our research, we found that serum $\mathrm{H}_{2} \mathrm{~S}$ levels were decreased in both hypothyroid patients and rats. Furthermore, FT4 and TT4 levels were improved by NaHS treatment in hypothyroid rats. These results revealed that $\mathrm{H}_{2} \mathrm{~S}$ had a role in protecting thyroid functions.

Subsequently, we studied how $\mathrm{H}_{2} \mathrm{~S}$ might influence thyroid functions. Mechanisms involved in thyroid hormone synthesis and secretion include oxidation of the TPO, iodination reaction, coupling reaction, iodide recycling and thyroid hormone 

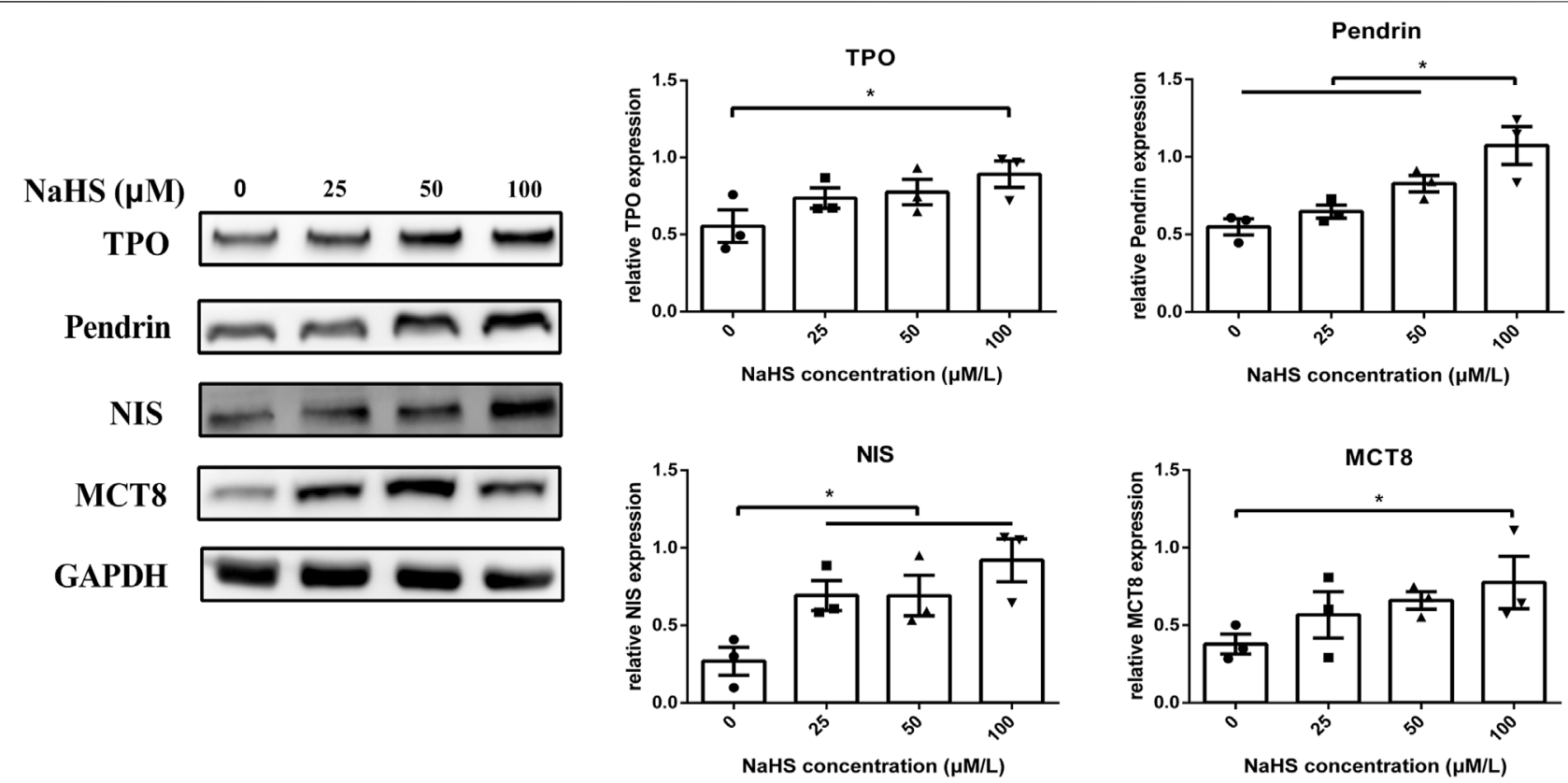

FIGURE 4 | Effect of $\mathrm{H}_{2} \mathrm{~S}$ on thyroid hormone synthesis- and secretion-related molecules in human primary thyrocytes. Changes in TPO, Pendrin, NIS, and MCT8 expression in human primary thyrocytes treated with different concentrations of NaHS by Western blot. They were upregulated in a concentration-dependent manner in NaHS. ${ }^{*} p<.05$, TPO: thyroid peroxidase, NIS: sodium/iodide symporter, MCT8: monocarboxylate transporter eight; NaHS, sodium hydrosulfide. Data are expressed as the mean \pm SEM, and all experiments were performed independently three times.

transport (Carvalho and Dupuy, 2017). TPO and TPO activity, Pendrin, NIS, and MCT8 were essential in this process. In vitro, we determined that the expression of TPO, Pendrin, NIS, and MCT8 was upregulated in a concentration-dependent manner in thyrocytes incubated with NaHS. TPO activity was also increased under NaHS treatment. These changes were consistent with the increase in FT4 levels. This result indicated that $\mathrm{H}_{2} \mathrm{~S}$ increased the synthesis and secretion of thyroid hormones in thyrocytes by upregulating the expression of associated molecules and TPO activity.

However, how $\mathrm{H}_{2} \mathrm{~S}$ induces this effect is not yet known. In the literature, Chen et al. showed that high glucose triggered reduced expression of thyroid hormone synthesis- and secretion-related proteins, which was accompanied by SIRT1 downregulation (Chen et al., 2019). We found that $\mathrm{H}_{2} \mathrm{~S}$ promoted the expression of TPO, NIS, Pendrin, MCT8 and TPO activity through SIRT1, which resulted in an increase in FT4 levels. When thyrocytes were incubated with EX527 to inhibit SIRT1, the above regulatory effect of NaHS disappeared. We proposed that $\mathrm{H}_{2} \mathrm{~S}$ promoted thyroid hormone synthesis and secretion by upregulating SIRT1.

Alleviated secretion of thyroid hormones by thyroid cells is one of the mechanisms of hypothyroidism (Gillam and Kopp, 2001). In our study, we demonstrated that $\mathrm{H}_{2} \mathrm{~S}$ improved thyroid hormone levels in hypothyroid rats and promoted the expression of thyroid hormone synthesis and secretion and TPO activity in human primary thyrocytes. $\mathrm{H}_{2} \mathrm{~S}$, as a gaseous signaling molecule, has been shown to be involved in multiple physiological and pathophysiological processes. Several
$\mathrm{H}_{2} \mathrm{~S}$-based therapy drugs have been developed to preclinical and early clinical stages, such as AP39 (Szczesny et al., 2014) and SG-1002 (Elrod et al., 2007). According to these developments, a better understanding of the $\mathrm{H}_{2} \mathrm{~S}$ mechanism in different organs will be necessary (Wallace and Wang, 2015). We found that $\mathrm{H}_{2} \mathrm{~S}$ has a protective effect on hypothyroidism; thus, $\mathrm{H}_{2} \mathrm{~S}$-related drugs may become an alternative treatment for hypothyroidism.

Our study had some limitation. Firstly, we found that $\mathrm{H}_{2} \mathrm{~S}$ promoted thyroid hormone synthesis and secretion by increasing the expression of related proteins in human primary thyrocytes. However, thyroid tissue specimens from rats were limited, and we did not explore whether $\mathrm{H}_{2} \mathrm{~S}$ regulated synthesis- and secretion-related molecules to restore thyroid hormones in hypothyroid rats. Secondly, we demonstrated that $\mathrm{H}_{2} \mathrm{~S}$ levels were reduced in hypothyroid patients and had a protective role in thyroid function, but we did not investigate the mechanism of the decrease in $\mathrm{H}_{2} \mathrm{~S}$ levels in thyrocytes. It was reported that the levels of CBS, CSE, and 3-MPST were changed in the muscles and liver tissues of hyperthyroid rats in different ways (Jeddi et al., 2019), which indicated that thyroid hormone influenced the expression of $\mathrm{H}_{2} \mathrm{~S}$-generating enzymes in rats. Further research will be performed to test whether the decreased $\mathrm{H}_{2} \mathrm{~S}$ level was induced by a hypothyroid status.

In conclusion, we confirmed that human thyrocytes produce $\mathrm{H}_{2} \mathrm{~S}$, and we found that CBS is the main $\mathrm{H}_{2} \mathrm{~S}$-generating enzyme. $\mathrm{H}_{2} \mathrm{~S}$ enhances the expression of thyroid hormone synthesis- and secretion-related molecules and TPO activity, which in turn 

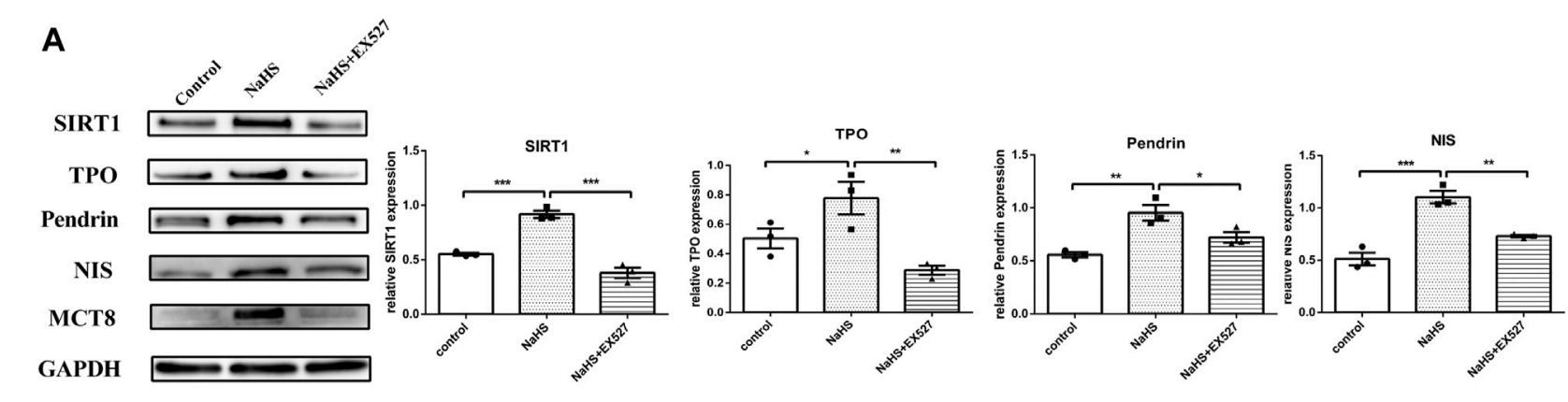
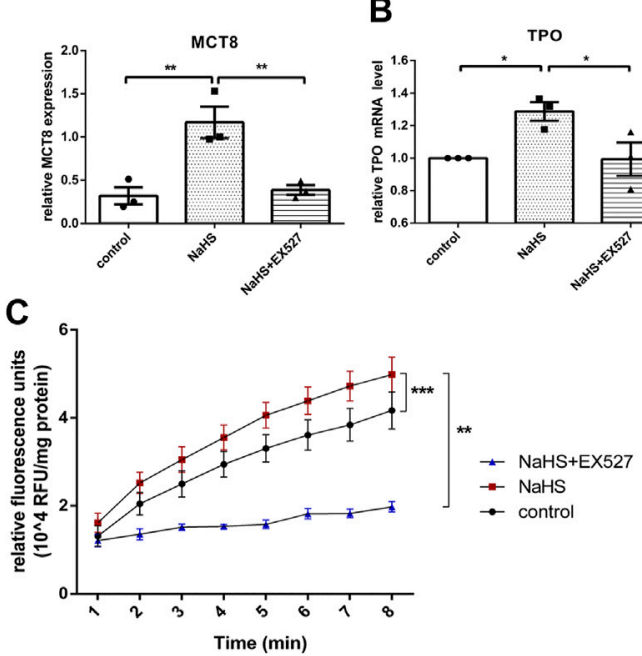

B
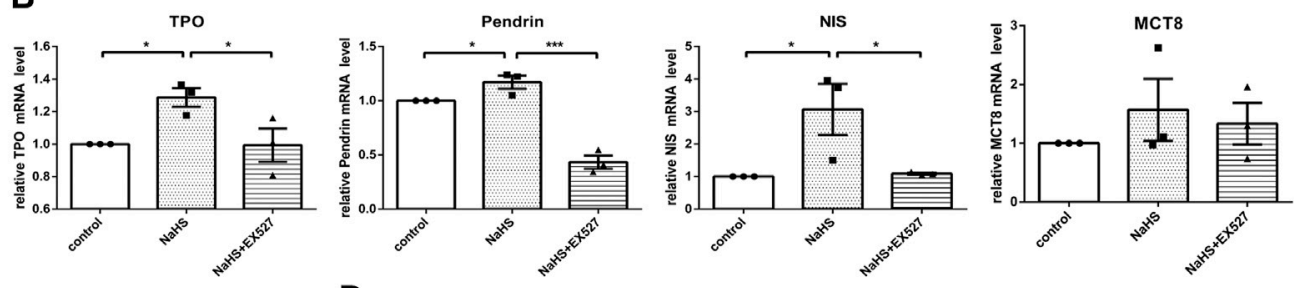

D

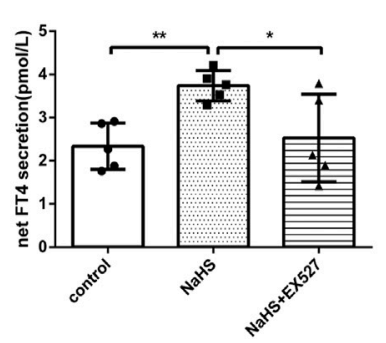

FIGURE 5 | The effect of $\mathrm{H}_{2} \mathrm{~S}$ on thyroid hormone and related molecules in human primary thyrocytes. (A,B) SIRT1, TPO, Pendrin, NIS, MCT8 protein and mRNA expression in human primary thyrocytes stimulated with NaHS or NaHS + EX527 assessed by real-time PCR and Western blot. (C) Extracellular TPO activity of thyrocytes stimulated with NaHS or NaHS + EX527 for 48 h. Fluorescence was normalized to the corresponding protein amounts. (D) The FT4 level in supernatants of human primary thyrocytes stimulated with NaHS or NaHS + EX527 for 48 h in chemiluminescence immunoassay. Net FT4 secretion meant that FT4 values in blank culture medium without thyrocytes were subtracted from FT4 content in thyrocyte culture supernatant. ${ }^{*} p<0.05,{ }^{* *} p<0.01,{ }^{\star \star *} p<0.001$. TPO: thyroid peroxidase, NIS: sodium/iodide symporter, MCT8: monocarboxylate transporter eight; NaHS, sodium hydrosulfide. Data are expressed as the mean \pm SEM, and all experiments were performed independently at least three times.

promotes the synthesis and secretion of thyroid hormones by upregulating SIRT1. Our work has shown that $\mathrm{H}_{2} \mathrm{~S}$ participates in the synthesis and secretion of thyroid hormones, which may provide a new view of $\mathrm{H}_{2} \mathrm{~S}$ for treating hypothyroidism.

\section{DATA AVAILABILITY STATEMENT}

The original contributions presented in the study are included in the article/Supplementary Material further inquiries can be directed to the corresponding author.

\section{ETHICS STATEMENT}

The studies involving human participants were reviewed and approved by the Biomedical Research Ethics Committee of Peking University First Hospital. The patients/participants provided their written informed consent to participate in this study. The animal study was reviewed and approved by Animal Research Ethics Committee of Peking University First Hospital. Written informed consent was obtained from the owners for the participation of their animals in this study. Written informed consent was obtained from the individual(s) for the publication of any potentially identifiable images or data included in this article.

\section{AUTHOR CONTRIBUTIONS}

$\mathrm{XZ}$ and YG designed this experiment. JZ provided advise for our study. XZ, YC, YY, YH, YZ, and LZ collected specimens for this study. $\mathrm{HJ}$ and $\mathrm{XW}$ provided technical guidance for the $\mathrm{H}_{2} \mathrm{~S}$-selective sensor and $\mathrm{H}_{2} \mathrm{~S}$ fluorescent probe. $\mathrm{XZ}$ performed the research. XZ conducted the data analysis and wrote paper. YG revised this article. All authors reviewed the manuscript and approved manuscript submission and publication. 


\section{FUNDING}

This work was supported by the National Natural Science Foundation of China (grant numbers 81770783 and 82170801).

\section{REFERENCES}

Abramowicz, M. J., Targovnik, H. M., Varela, V., Cochaux, P., Krawiec, L., Pisarev, M. A., et al. (1992). Identification of a Mutation in the Coding Sequence of the Human Thyroid Peroxidase Gene Causing Congenital Goiter. J. Clin. Invest. 90 (4), 1200-1204. doi:10.1172/JCI115981

Bagchi, N., and Fawcett, D. M. (1973). Role of Sodium Ion in Active Transport of Iodide by Cultured Thyroid Cells. Biochim. Biophys. Acta 318 (2), 235-251. doi:10.1016/0005-2736(73)90117-x

Biondi, B., and Wartofsky, L. (2014). Treatment with Thyroid Hormone. Endocr. Rev. 35 (3), 433-512. doi:10.1210/er.2013-1083

Biondi, B. (2012). Mechanisms in Endocrinology: Heart Failure and Thyroid Dysfunction. Eur. J. Endocrinol. 167 (5), 609-618. doi:10.1530/EJE-12-0627

Braunstein, A. E., Goryachenkova, E. V., and Lac, N. D. (1969). Reactions Catalysed by Serine Sulfhydrase from Chicken Liver. Biochim. Biophys. Acta 171 (2), 366-368. doi:10.1016/0005-2744(69)90173-9

Carvalho, D. P., and Dupuy, C. (2017). Thyroid Hormone Biosynthesis and Release. Mol. Cel Endocrinol. 458, 6-15. doi:10.1016/j.mce.2017.01.038

Chen, X. J., Gong, X. H., Jie, J. P., Yu, W. H., Chen, X., Du, X., et al. (2019). Receptor for Advanced Glycation End Products Reveals a Mechanism Regulating Thyroid Hormone Secretion through the SIRT1/Nrf2 Pathway. J. Cel Biochem. 120 (3), 4582-4598. doi:10.1002/jcb.27747

Chiku, T., Padovani, D., Zhu, W., Singh, S., Vitvitsky, V., and Banerjee, R. (2009). H2S Biogenesis by Human Cystathionine Gamma-Lyase Leads to the Novel Sulfur Metabolites Lanthionine and Homolanthionine and Is Responsive to the Grade of Hyperhomocysteinemia. J. Biol. Chem. 284 (17), 11601-11612. doi:10. 1074/jbc.M808026200

Di Cosmo, C., Liao, X. H., Dumitrescu, A. M., Philp, N. J., Weiss, R. E., and Refetoff, S. (2010). Mice Deficient in MCT8 Reveal a Mechanism Regulating Thyroid Hormone Secretion. J. Clin. Invest. 120 (9), 3377-3388. doi:10.1172/JCI42113

Du, C., Lin, X., Xu, W., Zheng, F., Cai, J., Yang, J., et al. (2019). Sulfhydrated Sirtuin-1 Increasing its Deacetylation Activity Is an Essential Epigenetics Mechanism of Anti-Atherogenesis by Hydrogen Sulfide. Antioxid. Redox Signal. 30 (2), 184-197. doi:10.1089/ars.2017.7195

Elrod, J. W., Calvert, J. W., Morrison, J., Doeller, J. E., Kraus, D. W., Tao, L., et al. (2007). Hydrogen Sulfide Attenuates Myocardial Ischemia-Reperfusion Injury by Preservation of Mitochondrial Function. Proc. Natl. Acad. Sci. U S A. 104 (39), 15560-15565. doi:10.1073/pnas.0705891104

Garber, J. R., Cobin, R. H., Gharib, H., Hennessey, J. V., Klein, I., Mechanick, J. I., et al. (2012). Clinical Practice Guidelines for Hypothyroidism in Adults: Cosponsored by the American Association of Clinical Endocrinologists and the American Thyroid Association. Endocr. Pract. 18 (6), 988-1028. doi:10. 4158/EP12280.GL

Gillam, M. P., and Kopp, P. (2001). Genetic Defects in Thyroid Hormone Synthesis. Curr. Opin. Pediatr. 13 (4), 364-372. doi:10.1097/00008480200108000-00014

Giordano, C., Stassi, G., De Maria, R., Todaro, M., Richiusa, P., Papoff, G., et al. (1997). Potential Involvement of Fas and its Ligand in the Pathogenesis of Hashimoto's Thyroiditis. Science 275 (5302), 960-963. doi:10.1126/science.275. 5302.960

Godlewska, M., Góra, M., Buckle, A. M., Porebski, B. T., Kemp, E. H., Sutton, B. J., et al. (2014). A Redundant Role of Human Thyroid Peroxidase Propeptide for Cellular, Enzymatic, and Immunological Activity. Thyroid 24 (2), 371-382. doi:10.1089/thy.2013.0127

Guan, R., Cai, Z., Wang, J., Ding, M., Li, Z., Xu, J., et al. (2019). Hydrogen Sulfide Attenuates Mitochondrial Dysfunction-Induced Cellular Senescence and Apoptosis in Alveolar Epithelial Cells by Upregulating Sirtuin 1. Aging (Albany NY) 11 (24), 11844-11864. doi:10.18632/aging.102454

\section{SUPPLEMENTARY MATERIAL}

The Supplementary Material for this article can be found online at: https://www.frontiersin.org/articles/10.3389/fphar.2022.838248/ full\#supplementary-material

Guan, R., Wang, J., Cai, Z., Li, Z., Wang, L., Li, Y., et al. (2020). Hydrogen Sulfide Attenuates Cigarette Smoke-Induced Airway Remodeling by Upregulating SIRT1 Signaling Pathway. Redox Biol. 28, 101356. doi:10.1016/j.redox.2019. 101356

Huang, P., Chen, S., Wang, Y., Liu, J., Yao, Q., Huang, Y., et al. (2015). Downregulated CBS/H2S Pathway Is Involved in High-Salt-Induced Hypertension in Dahl Rats. Nitric Oxide 46, 192-203. doi:10.1016/j.niox.2015.01.004

Jeddi, S., Gholami, H., Gheibi, S., Kashfi, K., and Ghasemi, A. (2019). Altered Gene Expression of Hydrogen Sulfide-Producing Enzymes in the Liver and Muscles Tissues of Hyperthyroid Rats. J. Cel Physiol. 234 (10), 17937-17945. doi:10. $1002 /$ jcp. 28426

Li, Y., Teng, D., Ba, J., Chen, B., Du, J., He, L., et al. (2020). Efficacy and Safety of Long-Term Universal Salt Iodization on Thyroid Disorders: Epidemiological Evidence from 31 Provinces of Mainland China. Thyroid 30 (4), 568-579. doi:10.1089/thy.2019.0067

Muangpaisan, W., Petcharat, C., and Srinonprasert, V. (2012). Prevalence of Potentially Reversible Conditions in Dementia and Mild Cognitive Impairment in a Geriatric Clinic. Geriatr. Gerontol. Int. 12 (1), 59-64. doi:10.1111/j.1447-0594.2011.00728.x

Mustafa, A. K., Gadalla, M. M., Sen, N., Kim, S., Mu, W., Gazi, S. K., et al. (2009). H2S Signals through Protein S-Sulfhydration. Sci. Signal. 2 (96), ra72. doi:10. 1126/scisignal.2000464

Nilsson, M., Husmark, J., Nilsson, B., Tisell, L. E., and Ericson, L. E. (1996). Primary Culture of Human Thyrocytes in Transwell Bicameral Chamber: Thyrotropin Promotes Polarization and Epithelial Barrier Function. Eur. J. Endocrinol. 135 (4), 469-480. doi:10.1530/eje.0.1350469

Pan, L. L., Liu, X. H., Gong, Q. H., Yang, H. B., and Zhu, Y. Z. (2012). Role of Cystathionine $\gamma$-lyase/hydrogen Sulfide Pathway in Cardiovascular Disease: a Novel Therapeutic Strategy? Antioxid. Redox Signal. 17 (1), 106-118. doi:10. 1089/ars.2011.4349

Ralli, M., Angeletti, D., Fiore, M., D’Aguanno, V., Lambiase, A., Artico, M., et al. (2020). Hashimoto's Thyroiditis: An Update on Pathogenic Mechanisms, Diagnostic Protocols, Therapeutic Strategies, and Potential Malignant Transformation. Autoimmun. Rev. 19 (10), 102649. doi:10.1016/j.autrev. 2020.102649

Sen, N., Paul, B. D., Gadalla, M. M., Mustafa, A. K., Sen, T., Xu, R., et al. (2012). Hydrogen Sulfide-Linked Sulfhydration of NF-kB Mediates its Antiapoptotic Actions. Mol. Cel 45 (1), 13-24. doi:10.1016/j.molcel.2011.10.021

Shibuya, N., Tanaka, M., Yoshida, M., Ogasawara, Y., Togawa, T., Ishii, K., et al. (2009). 3-Mercaptopyruvate Sulfurtransferase Produces Hydrogen Sulfide and Bound Sulfane Sulfur in the Brain. Antioxid. Redox Signal. 11 (4), 703-714. doi:10.1089/ARS.2008.2253

Stassi, G., and De Maria, R. (2002). Autoimmune Thyroid Disease: New Models of Cell Death in Autoimmunity. Nat. Rev. Immunol. 2 (3), 195-204. doi:10.1038/ nri750

Szczesny, B., Módis, K., Yanagi, K., Coletta, C., Le Trionnaire, S., Perry, A., et al. (2014). AP39, a Novel Mitochondria-Targeted Hydrogen Sulfide Donor, Stimulates Cellular Bioenergetics, Exerts Cytoprotective Effects and Protects against the Loss of Mitochondrial DNA Integrity in Oxidatively Stressed Endothelial Cells In Vitro. Nitric Oxide 41, 120-130. doi:10.1016/j.niox.2014. 04.008

Taylor, J. P., Metcalfe, R. A., Watson, P. F., Weetman, A. P., and Trembath, R. C. (2002). Mutations of the PDS Gene, Encoding Pendrin, Are Associated with Protein Mislocalization and Loss of Iodide Efflux: Implications for Thyroid Dysfunction in Pendred Syndrome. J. Clin. Endocrinol. Metab. 87 (4), 1778-1784. doi:10.1210/jcem.87.4.8435

Tian, X., Zhou, D., Zhang, Y., Song, Y., Zhang, Q., Bu, D., et al. (2021). Persulfidation of Transcription Factor FOXO1 at Cysteine 457: A Novel Mechanism by Which H2S Inhibits Vascular Smooth Muscle Cell Proliferation. J. Adv. Res. 27, 155-164. doi:10.1016/j.jare.2020.06.023 
Tiller, D., Ittermann, T., Greiser, K. H., Meisinger, C., Agger, C., Hofman, A., et al. (2016). Association of Serum Thyrotropin with Anthropometric Markers of Obesity in the General Population. Thyroid 26 (9), 1205-1214. doi:10.1089/thy. 2015.0410

Turbat-Herrera, E. A., Kilpatrick, M. J., Chen, J., Meram, A. T., Cotelingam, J., Ghali, G., et al. (2018). Cystathione $\beta$-Synthase Is Increased in Thyroid Malignancies. Anticancer Res. 38 (11), 6085-6090. doi:10.21873/anticanres. 12958

Untereiner, A. A., Fu, M., Módis, K., Wang, R., Ju, Y., and Wu, L. (2016). Stimulatory Effect of CSE-Generated H2S on Hepatic Mitochondrial Biogenesis and the Underlying Mechanisms. Nitric Oxide 58, 67-76. doi:10. 1016/j.niox.2016.06.005

Wallace, J. L., and Wang, R. (2015). Hydrogen Sulfide-Based Therapeutics: Exploiting a Unique but Ubiquitous Gasotransmitter. Nat. Rev. Drug Discov. 14 (5), 329-345. doi:10.1038/nrd4433

Wang, W., Chen, M., Jin, X., Li, X., Yang, Z., Lin, H., et al. (2018). H2S Induces Th1/Th2 Imbalance with Triggered NF- $\kappa B$ Pathway to Exacerbate LPS-Induce Chicken Pneumonia Response. Chemosphere 208, 241-246. doi:10.1016/j. chemosphere.2018.05.152

Wu, D., Li, J., Zhang, Q., Tian, W., Zhong, P., Liu, Z., et al. (2019). Exogenous Hydrogen Sulfide Regulates the Growth of Human Thyroid Carcinoma Cells. Oxid. Med. Cel Longev. 2019, 6927298. doi:10.1155/2019/6927298

Xin, H., Wang, M., Tang, W., Shen, Z., Miao, L., Wu, W., et al. (2016). Hydrogen Sulfide Attenuates Inflammatory Hepcidin by Reducing IL-6 Secretion and Promoting SIRT1-Mediated STAT3 Deacetylation. Antioxid. Redox Signal. 24 (2), 70-83. doi:10.1089/ars.2015.6315

Zhang, L. M., Jiang, C. X., and Liu, D. W. (2009). Hydrogen Sulfide Attenuates Neuronal Injury Induced by Vascular Dementia via
Inhibiting Apoptosis in Rats. Neurochem. Res. 34 (11), 1984-1992. doi:10.1007/s11064-009-0006-9

Zhang, D., Wang, X., Tian, X., Zhang, L., Yang, G., Tao, Y., et al. (2018). The Increased Endogenous Sulfur Dioxide Acts as a Compensatory Mechanism for the Downregulated Endogenous Hydrogen Sulfide Pathway in the Endothelial Cell Inflammation. Front. Immunol. 9, 882. doi:10.3389/ fimmu.2018.00882

Zhao, C., Gao, Y., Yu, N., Li, T., Zhang, Y., Zhang, H., et al. (2018). Unidirectional Transport of IgG by Neonatal Fc Receptor in Human Thyrocytes Varies across Different IgG Subclasses. Mol. Cel Endocrinol. 477, 103-111. doi:10.1016/j.mce. 2018.06.006

Conflict of Interest: The authors declare that the research was conducted in the absence of any commercial or financial relationships that could be construed as a potential conflict of interest.

Publisher's Note: All claims expressed in this article are solely those of the authors and do not necessarily represent those of their affiliated organizations, or those of the publisher, the editors and the reviewers. Any product that may be evaluated in this article, or claim that may be made by its manufacturer, is not guaranteed or endorsed by the publisher.

Copyright (c) 2022 Zhao, Cao, Jin, Wang, Zhang, Zhang, Yu, Huang, Gao and Zhang. This is an open-access article distributed under the terms of the Creative Commons Attribution License (CC BY). The use, distribution or reproduction in other forums is permitted, provided the original author(s) and the copyright owner(s) are credited and that the original publication in this journal is cited, in accordance with accepted academic practice. No use, distribution or reproduction is permitted which does not comply with these terms. 